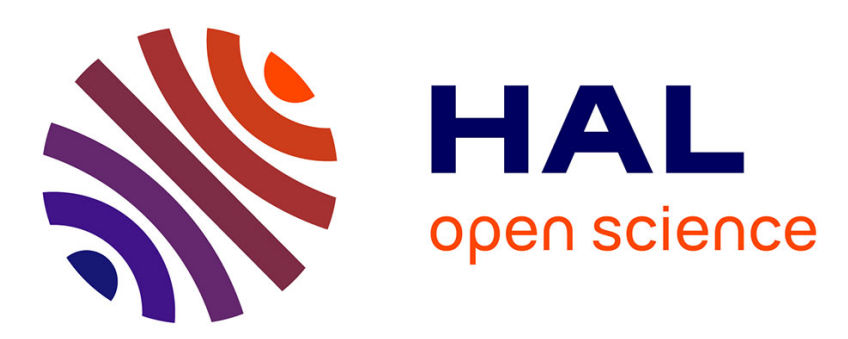

\title{
Design of a Naturally Cooled High Frequency Integrated Magnetic Component
}

Aiman Kerim, Jean-Paul Ferrieux, James Roudet, Stéphane Catellani

\section{To cite this version:}

Aiman Kerim, Jean-Paul Ferrieux, James Roudet, Stéphane Catellani. Design of a Naturally Cooled High Frequency Integrated Magnetic Component. Power Electronics Specialists Conference PESC 08, Jun 2008, Rhodes, Greece. hal-00292684

\section{HAL Id: hal-00292684 https://hal.science/hal-00292684}

Submitted on 2 Jul 2008

HAL is a multi-disciplinary open access archive for the deposit and dissemination of scientific research documents, whether they are published or not. The documents may come from teaching and research institutions in France or abroad, or from public or private research centers.
L'archive ouverte pluridisciplinaire HAL, est destinée au dépôt et à la diffusion de documents scientifiques de niveau recherche, publiés ou non, émanant des établissements d'enseignement et de recherche français ou étrangers, des laboratoires publics ou privés. 


\title{
Design of a Naturally Cooled High Frequency Integrated Magnetic Component
}

\author{
Aiman KERIM, Jean Paul FERRIEUX, James ROUDET and Stéphane CATELLANI \\ Grenoble Electrical Engineering Laboratory \\ ENSIEG - BP46 \\ 38402 St MARTIN D'HERES Cedex FRANCE
}

\begin{abstract}
A methodology for designing naturally cooled high frequency integrated magnetic component is presented. Windings losses are analytically estimated, and then improved using Finite Elements calculation.
\end{abstract}

The component geometry determines the maximal temperature on the surface of component by taking account the natural air convection and radiation effects. During its thermal stability, a magnetic component (windings, core, and isolation) could have a homogenous temperature in all its parts because of the good thermal conductivity of copper and ferrites.

A prototype of $500 \mathrm{~W}, 48 \mathrm{~V}$ half bridge integrated currentdoubler rectifier is implemented. Component temperature was simply detected using infrared camera.

This methodology could easily be integrated in computer aided design tools recently developed for designing magnetic component.

\section{INTRODUCTION}

Automated conception for high frequency discrete magnetic components [1], [2], transformers and inductors, reduces time, effort, human errors and also it is more compatible with optimization lines.

For an integrated magnetic component, more difficulties will be introduced like the neighboring of inductor and transformer windings with different current waveforms in the window area and the air gapped effects. So more simplifications will be required to achieve a design methodology which can be integrated in such computer tools.

In this paper, we present a methodology for designing naturally cooled high frequency integrated magnetic structure. An application for $500 \mathrm{~W}, 48 \mathrm{~V}$ half-bridge integrated currentdoubler rectifier is implemented.

\section{STRUCTURE OPERATION}

The current-doubler rectifier, shown in Fig. 1, has been integrated into a single magnetic core [3], [4]. The overall efficiency treated in [3], [4], was simply studied using DC winding losses as a comparative point, so losses due to air gap effect and classical eddy currents (proximity and skin effects), were ignored.

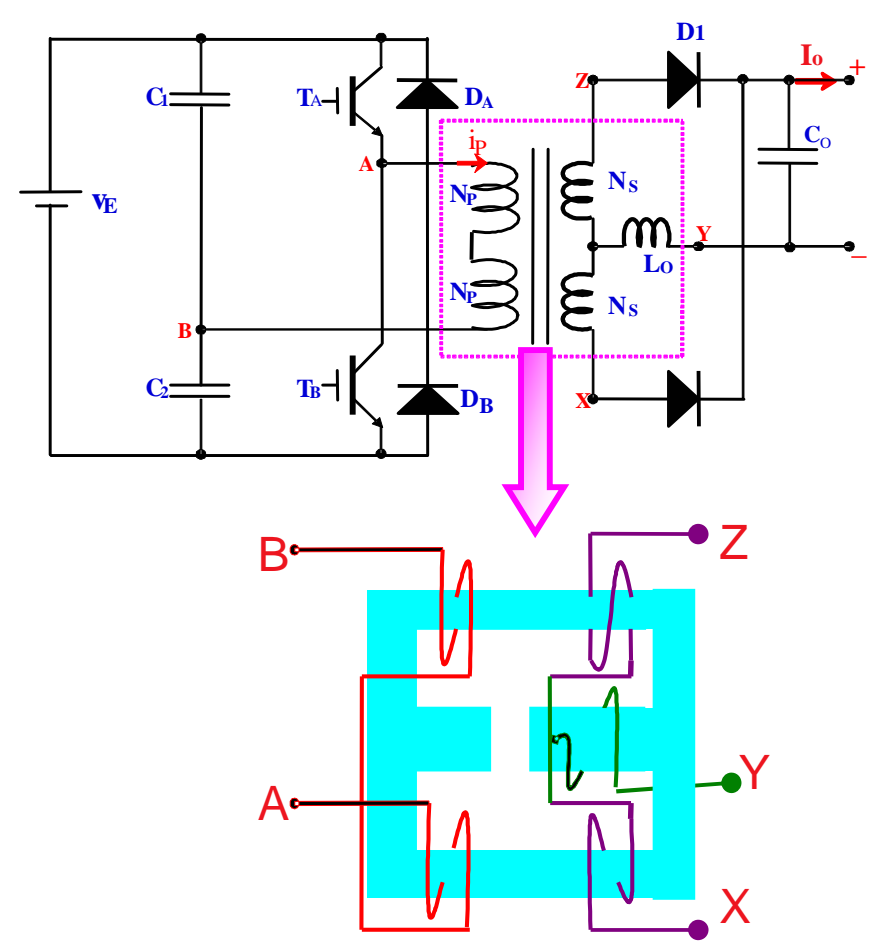

Figure1: Half-bridge converter using current doubler rectifier with the integrated magnetic component.

\section{DESIGN CONSIDERATIONS}

\section{A. Core specifications}

\section{Core material}

A core material determines power losses as a function of magnetic inductions with frequency and temperature as parameters.

\section{Core shape}

Cores shapes influence directly on the electromagnetic emissivity and on the thermal dissipation through the outer surface to ambience. 


\section{B. Windings losses}

To maintain the one dimensional solution of the magnetic field in the core window, we suppose the following:

1) Air gap effects could be neglected using the techniques proposed in [5],[6] where fringing flux can be modified and still very close to the air gap, hence the presence of onedimensional magnetic field in the core window becomes evident.

2) The presence of one-dimensional magnetic field allows the primary and secondary winding losses to be estimated using Dowell [7] or Ferreira method.

3) For the center leg windings, conduction losses will only be considered because of the reduced output current ripple.

So for primary and secondary windings, losses could be estimated using the following expressions:

$$
P_{c u}=\frac{\gamma}{2}\left[\left(\frac{\sinh \gamma+\sin \gamma}{\cosh \gamma-\cos \gamma}\right)+\left(\frac{\sinh \gamma-\sin \gamma}{\cosh \gamma+\cos \gamma}\right) \cdot(2 m-1)^{2}\right] \cdot R_{c}
$$

Where $(\gamma=\Delta / \delta): \Delta$ is the thickness of the foil and, $\delta$ is the skin depth, $R_{d c}$ is the DC resistance of the foil layer and $P_{c u}$ is the dissipated power from the $m$ 'th foil layer. For windings constructed using Litz wire, losses could be estimated using the expressions indicated in [8].

For the center leg windings:

$$
P_{c u c}=R_{d c c} I_{o}^{2}
$$

Where $R_{d c . c}$ is the total DC resistance of the center leg windings.

\section{Heat transfer}

Heat can be transferred through the component surface to the ambient by two ways: radiation and convection. Radiated heat could be estimated using Stefan - Boltzmann law defined as:

$$
P_{r a d}=5.710^{-8} E \cdot A \cdot \eta \cdot\left(T_{\max }^{4}-T_{a m b}{ }^{4}\right)
$$

Where $E$ is the emissivity of the component surface, $\eta$ presents the blockage effect of the desk, $A$ is the total surface of the component in $\left[\mathrm{m}^{2}\right]$ and $T_{\max }, T_{a m b}$ are the maximal and ambient temperature respectively in Kelvin.

Thermal simulation of cubic objects using Flotherm shows that $\eta=1$ for the upper horizontal surface, and $\eta=0.5 \sim 0.7$ for low profile structures.

Free convection is expressed using Newton's law as:

$$
P_{\text {conv }}=\theta A\left(T_{\max }-T_{a m b}\right)
$$

Where $\theta$ is the average convection coefficient defined for horizontal and vertical positions [9], $A$ is the vertical or horizontal surface area in $\left(\mathrm{m}^{2}\right)$.
Power dissipated through the upper horizontal surface $A_{u p}$ is given as:

$$
P_{c o n, h}=\theta_{u p} A_{u p}\left(T_{\max }-T_{a m b}\right)
$$

The average convection heat transfer coefficient $\theta_{u p}$ of the upper horizontal surface is given by:

$$
\begin{aligned}
& \theta_{u p}=0.55 \frac{\left(T_{\max }-T_{a m b}\right)^{0.25}}{L_{c r}^{0.25}} \text { for } R a_{L} \leq 10^{4} \\
& \theta_{u p}=0.61 \frac{\left(T_{\max }-T_{a m b}\right)^{0.25}}{L_{c r}^{0.25}} \text { for } 10^{4}<R a_{L}<10^{5} \\
& \theta_{u p}=0.68 \frac{\left(T_{\max }-T_{a m b}\right)^{0.25}}{L_{c r}^{0.25}} \text { for } 10^{5}<R a_{L}
\end{aligned}
$$

Where $L_{c r}$ is the characteristic length of the horizontal surface, it is defined as:

$L_{c r}=\frac{A_{u p}}{P_{e r}}$

$P_{e r}$ is the perimeter of the surface in $(\mathrm{m})$ and $\mathrm{Ra}_{\mathrm{L}}$ is Rayleigh number.

These values of $\theta_{u p}$ were empirically extracted using a thermal simulation tool (Flotherm) from 45 cubic objects with heights, lengths and widths varied from $5(\mathrm{~mm})$ to 150 (mm).

While $\mathrm{A}_{\text {up }}$ can be calculated as: $A_{u p}=(w+2 \lambda)(2 \lambda+l)$

While $l$ and $w$ are the length and the width of the core in (m), $\lambda$ is the width of transformer windings (primary and secondary) in (m), and can be calculated as:

$$
\frac{S_{t r}}{S_{w}}=\frac{\lambda \cdot h}{b \cdot h}=\frac{k_{c u}\left(N_{p} S_{p}+N_{s} S_{s}\right)}{k_{c u}\left(N_{p} S_{p}+N_{s} S_{s}+N_{c} S_{c}\right)}
$$

Where $S_{P}, S_{s}$ and $S_{c}$ are the wire sections of the primary, secondary and central winding respectively, $S_{t r}$ and $S_{w}$ are the surface area of transformer (primary and secondary) windings and window area respectively and $h$ is height of windings area.

Recognizing that [10]:

The output voltage $V_{o}$ is given as:

$$
V_{o}=2 \alpha \cdot m V_{a b}
$$

And secondary windings are calculated by:

$$
N_{s}=2 m N_{p}
$$

Central leg windings are given such:

$$
N_{c}=\frac{L . I_{o \max }}{B_{c \max } A_{c}}-\frac{N_{s}}{2}
$$


Where $m$ is the transformer ratio, $L$ is the output filtering inductor and $B_{c \max }$ is the magnetic induction in the centre leg.

Supposing that in all windings we have the same current density $J$, then:

$S_{p}=I_{\text {prms }} / J, S_{s}=I_{\text {srms }} / J$ and $S_{c}=I_{o} / J$.

Where $J$ is the current density $\left(\mathrm{A} / \mathrm{mm}^{2}\right)$.

The rms values of primary secondary and central currents are:

$$
\begin{aligned}
& I_{\text {prms }}=\sqrt{2 \alpha} \cdot m I_{o} \\
& I_{\text {srms }}=\sqrt{2 \alpha+1} \cdot \frac{I_{o}}{2} \\
& I_{\text {crms }}=I_{o}
\end{aligned}
$$

Where $I_{o}$ is the out put current, and $\alpha$ is the duty cycle.

$$
\begin{aligned}
A_{o} & =\frac{V_{a b}}{4 N_{P} B_{\mu \max }} \alpha T \\
A_{c} & =2 A_{o}
\end{aligned}
$$

Where $B_{\mu \max }$ is the alternative magnetic induction in $(\mathrm{T}), A_{o}$ and $A_{c}$ are the cross-sectional area of the outer and central leg in $\left(\mathrm{m}^{2}\right)$.

Introducing the following factors:

$$
\begin{aligned}
& k_{\mu}=\frac{B_{c \max }}{B_{\mu \max }} \\
& k_{\text {rip }}=\frac{\Delta I_{o}}{I_{o}}
\end{aligned}
$$

Where $\Delta I_{o}$ is peak to peak output current ripple.

Substituting $(7,15)$ in $(6)$ and Multiplying by $\left(A_{c} / A_{c}\right)$, we obtain:

$$
\lambda=\frac{K_{\mu} K_{r i p}(\sqrt{2 \alpha}+\sqrt{2 \alpha+1}) b}{K_{\mu} K_{\text {rip }}(\sqrt{2 \alpha}+\sqrt{2 \alpha+1}-1)+2(1-2 \alpha)\left(1+0.5 K_{\text {rip }}\right)}
$$

Therefore, $\lambda$ can be expressed in equation (16) as a fraction of the windings area width $b$, Fig. 2 .

Then the power dissipated through the vertical surface $A_{v}$ could be expressed as:

$$
P_{c o n, v}=\theta_{v} A_{v}\left(T_{\max }-T_{a m b}\right)
$$

The convection heat transfer coefficient $\theta_{v}$ of the vertical surface is given by:

$$
\theta_{v}=1.42 \cdot \frac{\Delta T^{0.25}}{h^{0.25}}
$$

Overall vertical surfaces can be determined as:

$$
A_{v}=2 h(4 \lambda+l+w)
$$

Therefore, equation (17) can be rewritten as:

$$
P_{\text {con, },}=2.84 . h^{0.75}(4 \lambda+l+w)\left(T_{\max }-T_{a m b}\right)^{1.25}
$$
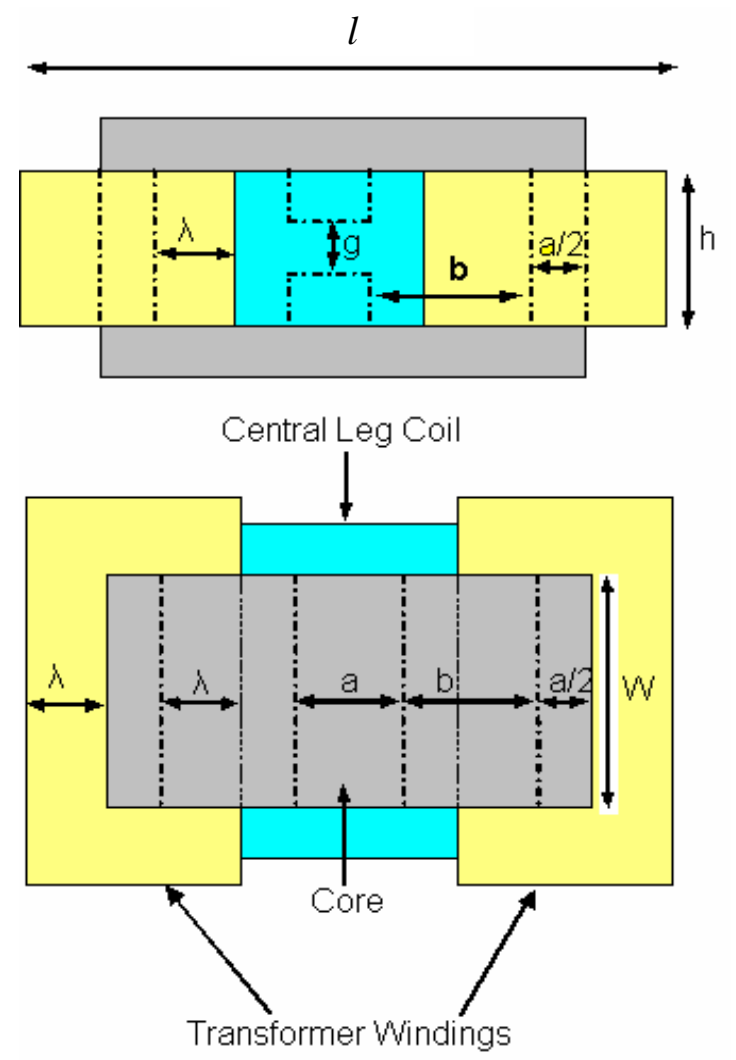

Fig.2. Perspective view of the integrated magnetic component with both core and windings.

\section{DESIGN PROCEDURE}

A. Inputs Specifications

The input specifications required to begin the design are:

$V_{a b}$ : Input voltage (V)

$V_{o}:$ Output voltage $(\mathrm{V})$

$P_{o}$ : Output Power (W)

$f$ : Frequency in Hertz $(\mathrm{Hz})$

$\alpha$ : Duty cycle

$K_{\text {rip }}$ : Output ripple factor $\left(K_{\text {rip }}=\Delta I_{o} / I_{o}\right)$.

$K \mu$ : Factor expressed as $\left(k_{\mu}=B_{\text {cmax }} / B_{\mu \max }\right)$.

$\mathrm{T}_{\max }, \mathrm{T}_{\mathrm{amb}}$ : Maximal and ambient temperature respectively.

B. Filtering Inductance $L$

The output inductance required to keep the output current ripple at the desired value is given by:

$$
L=\alpha \frac{\left(m V_{a b}-V_{o}\right)}{f \Delta I_{o}}
$$




\section{Initial selection of core size}

Product area $A_{P}$ (window area $W_{a} \times$ core section $A_{c}$ ) is defined [10] as:

$$
A_{P}=\frac{k_{c u}}{4 J \cdot f B_{\mu \max }}(\sqrt{2 \alpha}+\sqrt{2 \alpha+1}-1) P_{o}+\frac{k_{c u} L I_{o \max } I_{o}}{B_{C \max } J}
$$

Where arbitrary values of $B_{\mu \max }, J$ and $K_{\mu}$ are determined to make an initial selection of core size. Core material was selected using the performance factor: $P f=f . B$

\section{Turns}

Transformer ratio $\mathrm{m}$ using (8)

Primary windings $2 N_{p}$ using (14)

Secondary windings $N_{s}$ using (9)

Central leg windings $N_{c}$ using (10)

\section{E. Air gap length:}

$$
g=\mu_{0} \frac{\left(N_{c}+N_{s} / 2\right) I_{o \max }}{B_{c \max }}
$$

\section{F. Core losses}

Core losses can be expressed as:

$$
P_{f}=\gamma_{f} k_{f} f^{K_{1}}\left(\left(B_{\mu \max }+\frac{\Delta B_{c}}{2}\right)^{K_{2}} V_{\text {outer }}+2^{K_{1}}\left(\frac{\Delta B_{c}}{2}\right)^{K_{2}} V_{\text {cent }}\right)
$$

Where $K_{1}, K_{2}$ and $K_{f}$ are constants supplied by manufacturers, $\gamma_{f}$ is the mass density of the core material, $V_{\text {outer }}$ and $V_{c e n}$ are the outer and central part of core volume respectively in $\left(\mathrm{m}^{3}\right)$.

\section{G. Winding losses}

Defining the turns, wires sizes and layers, then windings losses $P_{c u}$ could be estimated using (1) and (2).

\section{H. Maximal Heat Dissipation}

Once the core is selected and all windings are calculated, then the maximal power dissipated $P_{d i s}$ can be calculated as:

$P_{\text {dis }}=P_{\text {conv }}+P_{\text {rad }}$

Where:

$P_{\text {conv }}=P_{\text {conv. } v}+P_{\text {conv.h }}$.

$P_{\text {rad }}=P_{\text {rad. } . v}+P_{\text {rad.h }}$.

Thermal balancing at the desired maximal temperature $T_{\max }$ occurs when:

$$
P_{d i s}=P_{c u}+P_{f}
$$

Note that we suppose that the maximal temperature is uniformly distributed on the component surface.

\section{EXPERIMENTAL APPLICATION}

The previous procedure was applied to design a half bridge integrated current-doubler rectifier with the following input specifications:

\begin{tabular}{|c|c|c|c|c|c|c|c|}
\hline $\begin{array}{c}V_{E} \\
(\mathrm{~V})\end{array}$ & $\begin{array}{c}V_{o} \\
(\mathrm{~V})\end{array}$ & $\begin{array}{c}P_{o} \\
{[\mathrm{~kW}]}\end{array}$ & $\begin{array}{c}f \\
(\mathrm{kHz})\end{array}$ & $K_{\text {rip }}$ & $K_{\mu}$ & $\begin{array}{c}\mathrm{T}_{\max } \\
\left({ }^{\circ} \mathrm{C}\right)\end{array}$ & $\alpha$ \\
\hline 380 & 48 & 0.5 & 150 & $20 \%$ & $65 \%$ & 85 & $43 \%$ \\
\hline
\end{tabular}

The selected core is E43/10/28 planar, with $2 \mathrm{~N}_{\mathrm{p}}=20, \mathrm{~N}_{\mathrm{s}}=7$ and $\mathrm{N}_{\mathrm{c}}=3$. Primary windings (20 turns) are constructed using a foil of $(7 \mathrm{~mm} \times 0,2 \mathrm{~mm})$ dimensions, secondary windings ( 7 turns) are constructed using a foil of $(2 / /: 9 \mathrm{~mm}$ $\mathrm{x} 0,2 \mathrm{~mm}$ ) and central windings ( 3 turns)with a foil of ( $2 / /: 4$ $\mathrm{mm} \times 0,3 \mathrm{~mm})$. The converter is experimentally tested and also simulated using 2D finite elements tool.

Winding losses are obtained by using finite elements simulation and are equal to $10 \mathrm{~W}$. Simulation results are presented in Table. I.

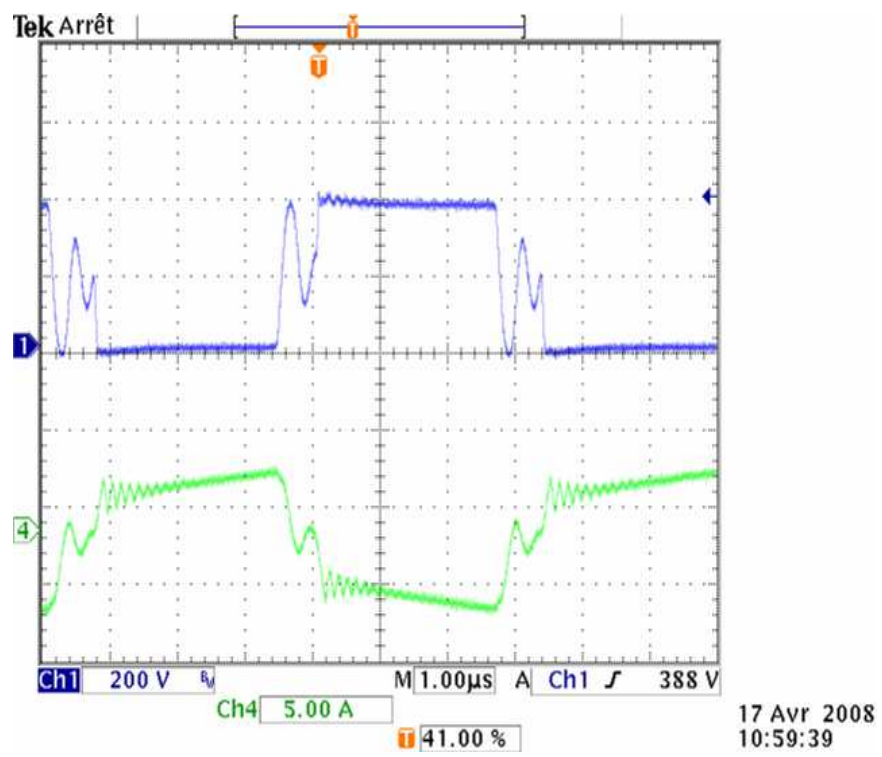

Fig. 3: Transistor voltage waveform in blue and primary current waveform in green.

TABLE I

ESTIMATED LOSSES IN THE 2D PLAN

\begin{tabular}{|c|c|c|c|}
\hline & $\begin{array}{c}\text { Primary } \\
\text { losses } \\
(\mathrm{W})\end{array}$ & $\begin{array}{c}\text { Secondary } \\
\text { losses } \\
(\mathrm{W})\end{array}$ & $\begin{array}{c}\text { Central leg } \\
\text { winding } \\
(\mathrm{W})\end{array}$ \\
\hline $\begin{array}{c}\text { 2D Numerical } \\
\text { estimation } \\
\text { (single air gap) }\end{array}$ & 4.23 & 5.6 & 0.178 \\
\hline $\begin{array}{c}\text { Analytical } \\
\text { estimation }\end{array}$ & 3.5 & 3.86 & 0.091 \\
\hline
\end{tabular}


Note that analytical estimation of the central leg winding in neglecting air gap effects equals $50 \%$ of the numerical estimation, but this difference equals $0.8 \%$ of global losses.

The difference between the two proposed estimations could be explained, on the one hand, by the edge effect not taken into account in the analytical method and, on the other hand, by the difference between primary and secondary windings.

Magnetic losses are also calculated using (26):

$P_{f}=1.48 \mathrm{~W}$

Then total losses are:

$P=P_{c u}+P_{\text {cu. }}+P_{f}$

$P=11.48 \mathrm{~W}$

Core specifications are listed in Table II.

TABLE II

CORE SPECIFICATIONS

\begin{tabular}{|c|c|c|c|c|c|}
\hline $\begin{array}{c}\text { Core } \\
\text { material }\end{array}$ & $K_{1}$ & $K_{2}$ & $\begin{array}{c}V_{\text {outer }} \\
\left(\mathrm{m}^{3}\right)\end{array}$ & $K_{f}$ & $\begin{array}{c}\gamma_{f} \\
\left(\mathrm{~kg} / \mathrm{m}^{3}\right)\end{array}$ \\
\hline $3 \mathrm{~F} 3$ & 1.24 & 2.6 & $10.8 \times 10^{-6}$ & $1.9 \times 10^{-3}$ & 4800 \\
\hline
\end{tabular}

The heat dissipated through the natural convection and radiation is calculated using with an emissivity factor $E=0.9$. Thermal specifications are listed in Table III.

TABLE II

THERMAL SPECIFICATIONS

\begin{tabular}{|c|c|c|c|c|}
\hline $\begin{array}{c}T_{a m b} \\
\left({ }^{\circ} \mathrm{C}\right)\end{array}$ & $\begin{array}{c}T_{\max } \\
\left({ }^{\circ} \mathrm{C}\right)\end{array}$ & $\begin{array}{c}P_{\text {conv, }} \\
(\mathrm{W})\end{array}$ & $\begin{array}{c}P_{\text {conv }, h} \\
(\mathrm{~W})\end{array}$ & $\begin{array}{c}P_{\text {rad }} \\
(\mathrm{W})\end{array}$ \\
\hline 20 & 85 & 1.84 & 0.923 & 11 \\
\hline
\end{tabular}

Then, the total dissipated power capability is $13.76 \mathrm{~W}$.

Note that dissipated power is higher than total losses, but these losses are computed using 2D model.

The following image Fig. 4 presents the temperature distribution of the integrated magnetic component at the nominal power captured using infra-red camera. The maximal temperature is $87^{\circ} \mathrm{C}$ on the surface of transformer windings.

Thermal measurements show that there is no significant difference between windings temperature $88{ }^{\circ} \mathrm{C}$ and core temperature $82^{\circ} \mathrm{C}$.

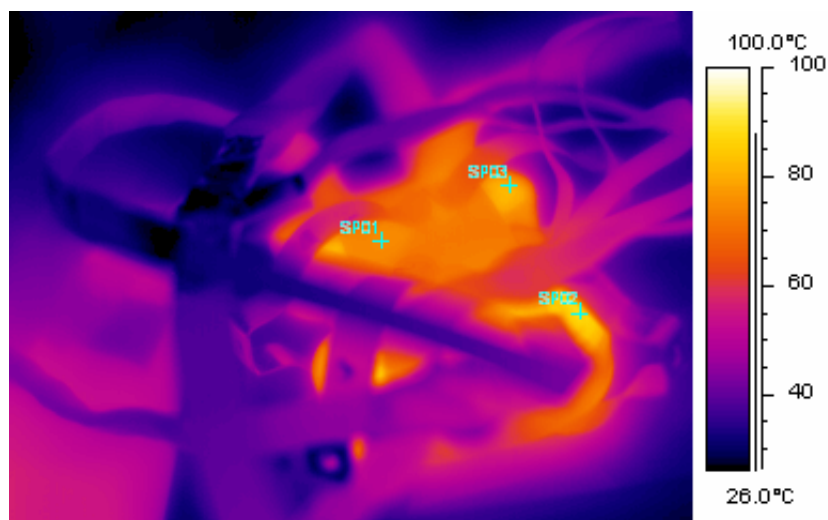

Fig. 4: Thermal image of the integrated component with its nominal power.

\section{CONCLUSION}

A simple methodology of integrated magnetic component designing is presented. High frequency windings losses were analytically treated in adapting the one dimensional solution of magnetic field to the integrated structure, and the losses were also computed using a FE tool. Thermal dissipation by natural convection and radiation was exploited to achieve a thermal balancing at the desired maximal temperature. This methodology was applied to design a half-bridge converter with an integrated magnetic component. The operating temperature of the integrated structure was simply captured using an infra-red camera. This methodology can be integrated in a computer aided design developed recently for classical components.

\section{REFERENCES}

[1] John G.Breslin and W. Gerard Hurley, "Computer Aided High Frequency Transformer Design Using An Optimized Methodology", IEEE Proceedings, pp. 277-280, July2000.

[2] Pawel M. Gradzki, Milan M. Jovanovic and Fred Lee, "Computer-Aided Design For High-Frequency Power Transformers", IEEE Proceedings, pp.336-343, March 1990.

[3] L. Yan, D. Qu and B. Lehman, "Integrated Magnetic Full Wave Converter with Flexible Output Inductor", in Proc. IEEE Applied Power Electronics Conference, vol. 18, pp. 670-678, March 2003

[4] J. Sun, F. Webb and V. Mehrotra, "Integrated Magnetics for Current-Doubler Rectifiers", IEEE Trans. Applied Power Electronics Conference, vol. 19, pp. 582-590, May2004.

[5] Ulrich Kirchenberger, Michael Marx and Dierk Schröder, “A Contribution to the Design Optimization of Resonant Inductors for High Power Resonant DC-DC Converters", IEEE Proceedings IAS, vol. 1, pp.994-1001, october1992.

[6] M. Meinhardt, M. Duffy, T. O’Donnell, S. O’Reilly, J. Flannery and C.O. Mathuna, "New Method for Integration of Resonant Inductor and Transformer-Design, Realization, Measurements", IEEE Proceedings APEC, vol. 2, pp.1168-1174, March1999.

[7] P. L. Dowell, "Effects of Eddy Currents in Transformer Windings", IEEE Proceedings, vol. 119, pp.1387-1394, August1966

[8] F. Tourkhani and P. Viarouge "Accurate Analytical Model of Winding Losses in Round Litz Wire Windings", IEEE Transactions on Magnetics, vol. 37, pp.538-543, January2001.

[9] Bernard Eyglunent, "Manuel de Thermique: Théorie et Pratique”, HERMES, Paris, 1997 (in French). 
[10] Aiman Kerim, Jean-Paul Ferrieux, James Roudet, Stéphane

Catellani, Hassan Benqassmi, "An Improved Design of a DCDC Converters Using An Integrated Magnetic Component", APEC, February 2008. 